\title{
DISCUSSION
}

\section{Greenfield ground response to EPBM tunnelling in London Clay}

\author{
J. R. STANDING*, D. SELEMETAS $\dagger$ and J. N. SHIRLAW $\ddagger$
}

\section{Contribution by J. N. Shirlaw}

The authors are to be congratulated on the very detailed measurements they have made of surface and subsurface movements during the construction of two parallel, earth pressure balance (EPB)-driven tunnels (Standing \& Selemetas, 2013). The extent and detail of the measurements are significantly greater than normal for such projects, and are potentially of great value in developing our understanding of the interaction between pressurised tunnel-boring machines (TBMs) and the ground.

In their conclusions, the authors state that

The pressurised face of the EPBM and tail-skin grouting led to outward displacements and increases in pore water pressure in the near vicinity of the TBM, extending about one tunnel diameter from the extrados.

The passage of the shield resulted in movements that were generally away from the tunnel, and positive excess pore pressures over the crown of the tunnel. This is clear in the results presented by the authors. However, there is an inconsistency between those movements/pore pressures and the face and grouting pressures reported by the authors. As shown in Table 3, the reported face and grouting pressures were $44 \%$ to $59 \%$ of the total overburden pressure, and $57 \%$ to $75 \%$ of the horizontal in-situ stress. If the pressures applied were significantly lower than the in-situ stresses in the ground, how could those pressures have caused local ground deformations that were generally away from the tunnel, and positive excess pore pressures just over the tunnel crown?

Because of the level of detail provided by the authors, it is possible to define the approximate location and magnitude of the maximum ground movements and pore pressures close to the TBM. These values/locations are summarised in Table 4. The values/locations given in Table 4 are mostly approximate, as they are either given approximately in the paper, or scaled off the figures in the paper. The authors' sign convention is followed except for horizontal movement, which is given as either away from or towards the relevant tunnel.

As can be seen from Table 4, the focus of the outward movements appears to have been located over the tail-skin of the TBMs, and not at the face or tail void. This can also be seen in the authors' Fig. 21. With reference to the vectors of movement closest to the TBM, this figure shows, for both drives

(a) very small, almost negligible, movements ahead of the face

(b) maximum outward displacement over the centre/rear of the TBM

(c) a reduction in outward displacement as the tail-skin

* Department of Civil and Environmental Engineering, Imperial College London, UK.

$\dagger$ Cementation Skanska Limited, Maple Cross, Rickmansworth, UK.

¥ Golder Associates (Singapore) Pte Ltd, Singapore.
Table 3. Comparison of the face and grout pressures with the insitu ground pressures

\begin{tabular}{l|c|c|c}
\hline & Unit & Up-line & Down-line \\
\hline Face pressure (FP) & $\mathrm{kPa}$ & 200 & 150 \\
Grout pressure (GP) & $\mathrm{kPa}$ & 160 & 200 \\
Overburden pressure & $\mathrm{kPa}$ & 340 & 340 \\
Horizontal in-situ pressure & $\mathrm{kPa}$ & 265 & 265 \\
FP/overburden & $\%$ & $58 \%$ & $44 \%$ \\
GP/overburden & $\%$ & $47 \%$ & $59 \%$ \\
FP/horizontal in situ & $\%$ & $75 \%$ & $57 \%$ \\
GP/horizontal in situ & $\%$ & $60 \%$ & $75 \%$ \\
\hline
\end{tabular}

moves beyond the monitoring point (i.e. where the tail void is grouted).

Tables 3 and 4, read together, indicate that the displacement was not due to either the face pressure or the tail void grouting pressure, but due to the passage of the shield skin through the ground.

The data provided by the authors include the thrust force as well as the face pressure. Converting the face pressure into the total force applied to the face, the remaining force, the residual force, is the force required to

(a) provide the force on the cutting tools

(b) overcome contact forces on the shield skin

(c) drag the trailing gear.

The residual force for the down-line tunnel was nearly double that applied to the up-line tunnel, as shown in Table 5. Items $(a)$ and (c) (above) should have been approximately the same for the two tunnel drives, so most of the difference in the residual force is likely to have been due to the difference in the contact force on the shield skins. It appears likely that the difference in the contact forces on the shield skins between the two tunnel drives was reasonably consistent with the difference in the measured heave close to the TBMs.

Part of the contact force on the shield skin, and the outward movement, could have been due to the $19 \mathrm{~mm}$ bead noted by the authors; however, while this could have accounted for much of the heave seen for the up-line tunnel, it could not account for the larger heave and residual force seen in the down-line tunnel.

Possible causes for the much higher residual force required to advance the down-line tunnel, compared with the up-line tunnel, could include the following.

(a) If the down-line TBM was slightly high at this point, and the TBM was being driven with overhang in order to move back towards the theoretical tunnel alignment, then a relatively small change in overhang could result in the tail-skin coming into direct contact with the ground.

(b) The small gap created around the skin by the bead could have become filled with grout: Bezuijen et al. (2012) discuss observations of grout flowing forward, and setting 
Table 4. Location and magnitude of maximum ground movements and pore pressures close to the TBM (note values are approximate)

\begin{tabular}{|c|c|c|c|c|c|}
\hline & Unit & Up-line & Where occurred & Down-line & Where occurred \\
\hline Maximum vertical movement over crown & $\mathrm{mm}$ & +15 & $10 \mathrm{~m}$ (end of tail-skin) & 40 & $7 \cdot 1 \mathrm{~m}$ (tail-skin) \\
\hline $\begin{array}{l}\text { Maximum orthogonal horizontal movement at tunnel } \\
\text { level }\end{array}$ & $\mathrm{mm}$ & 2 (away) & $9.9 \mathrm{~m}$ (end of tail-skin) & 2 (towards) & $9.9 \mathrm{~m}$ (end of tail-skin) \\
\hline Maximum positive excess pore pressure above crown & $\mathrm{kPa}$ & 96 & $-1 \mathrm{~m}$ (just ahead of cutterhead) & 200 & 7 m (tail-skin) \\
\hline
\end{tabular}

Table 5. Forces applied to the TBMs compared with the maximum heave directly over the TBMs

\begin{tabular}{l|c|c|c}
\hline & Unit & Up-line & Down-line \\
\hline Force to provide face pressure & $\mathrm{MN}$ & $10 \cdot 46$ & $7 \cdot 85$ \\
Total thrust force & $\mathrm{MN}$ & 16 & 18 \\
Residual force & $\mathrm{MN}$ & $5 \cdot 54$ & $10 \cdot 15$ \\
Maximum heave over tunnel & $\mathrm{mm}$ & 15 & 40 \\
\hline
\end{tabular}

on, the tail-skin of a slurry TBM. With the sand/cement/ fly-ash/bentonite grout used on this project, this could result in significant frictional forces between the skin and the ground

In order to obtain a better understanding of these movements and their cause(s), it would be useful to have more details of the measured forces on the TBMs. In particular, the force required to drag the trailing gear, and the force applied to the cutterhead. These forces are commonly measured on modern, pressurised TBMs.

A more detailed assessment of the measured forces would allow the force required to overcome the resistances on the shield skin to be established, and show how this value varied as the TBM was driven under the array. This may shed more light on the observed movements and changes in pore pressure.

It would also be appreciated if the authors would clarify if the 'bead' noted by them was a conventional bead, welded to the shield skin and outside the area cut by the cutterhead. EPB TBMs typically cut a diameter that is slightly larger than the shield, and have a taper along the skin, resulting in a gap around the skin but without the need to push a bead into the ground.

\section{Authors' reply}

The authors are most grateful to the discusser for his interest in their paper and the insightful discussion he has put forward. They are also again indebted to Mr Ivor Thomas, tunnel manager for BAM Nuttall, for his discussions and help in addressing some of the points raised, with particular emphasis on the TBM.

The discussion starts by observing the differences in the quoted TBM face and grout pressures in relation to the insitu ground stresses. The apparent anomaly is that outward ground movements, that is those directed away from the shield, were measured when the magnitude of the ground total stresses were reported to be considerably greater than either the face pressure or the grouting pressure applied behind the rings just beyond the rear of the shield. Increases in pore-water pressure were also recorded at the same time. The figures showing subsurface vertical and horizontal displacements (Figs 12 and 14 and Figs 16 and 19 respectively for the up-line and down-line drives) and pore-water pressures (Figs 15 and 20 for the up-line and down-line drives respectively) are then assessed to identify where the maximum magnitudes of change occurred in relation to the position of the TBM. Attention is drawn to the fact that the greatest increase in the magnitude of ground displacements occurs as the body of the TBM shield passes beneath the monitoring section, rather than when either the face or the tail void passes the same point. This can also be clearly interpreted from Fig. 21, which shows the resultant vectors of displacement at various positions of the TBM.

The face pressures were measured at the back of the plenum chamber by eight pressure transducers and the values given and shown in the paper represent an average from these (Figs 6(a) and 6(b)). The measured values are likely to be less than those at the face itself because of frictional losses as the muck passes through the cutterhead and into and through the plenum chamber. This is difficult to quantify as pressure measurements cannot be made directly at the face because of the rotating head and cutting of the soil. However, this does not affect the location where the maximum displacements were observed for either drive. It might help to explain the location of the maximum excess pore-water pressure for the up-line tunnel which was recorded just ahead of the face (cutterhead), but there is another factor that needs to be taken into account. The up-line TBM was stopped with the face $4 \mathrm{~m}$ in front of the monitoring section for a period of $9 \mathrm{~h}$. Up to this distance only small excess pore-water pressures were developed, as can be seen in Fig. 15(a); it is possible that excess pore pressures did not develop significantly because the A2 unit of the London Clay, present at the site, usually has the highest permeability of all London Clay units (Hight et al., 2003) and so dissipation would be rapid. Once the TBM restarted, excess pore-water pressures quickly developed, possibly because the ground around the TBM squeezed in during this 9-h period and larger thrusts were needed to start moving the TBM again. These excess porewater pressures dropped off equally quickly and were subsequently of only small magnitude (less than about $25 \mathrm{kPa}$ ). In the case of the down-line tunnel, excess pore-water pressures just above the crown developed to a maximum value when the TBM was about halfway past the section and these dropped rapidly as the rear of the shield passed (Fig. 20(b)). The position of this increase in excess pore-water pressure correlates well with the location of the maximum vertical displacement above the crown (see Table 4 in discussion above and Fig. 21(b) in the original paper).

The next step in the discussion is to consider the magnitude of the residual force for the two drives, this being the difference between the thrust force and the force determined from the face pressure. The residual force for the down-line drive is almost twice that of the up-line drive. Three potential contributing factors that make up the residual force are given

(a) providing force on the cutting tools

(b) overcoming friction along the shield

(c) dragging the trailing gear.

As pointed out, there are no known reasons why $(a)$ and $(c)$ should not be considered to be the same for both drives (e.g. there is no information about wheels locking up in the case of $(c)$ ). Unfortunately monitoring data relating to the force required to drag the trailing gear and that applied to the cutting tools are now unavailable. Two potential causes are 
suggested for the remaining factor $(b)$ relating to the force required to overcome contact forces on the shield. One relates to the adjustment of the shield to correct for vertical out-of-alignment and the other the filling of the void between the shield and the ground (formed from the bead) by grout from the tail-skin grouting.

Although records are not available to confirm whether the down-line TBM was driven with an overhang, in other words with the body of the TBM shield tilted slightly downwards, this option could certainly be valid. The second reason is thought to be much less likely because in instances when it has been necessary for the tunnelling contractor to excavate around the rear of the shield of similar TBMs, no signs of grout have been observed (Thomas, personal communication, 2014). The hard-faced bead used for both drives was welded directly onto the cutterhead. Significantly, the shield was not tapered along its length and so frictional forces either from squeezing (as related to the restarting of the up-line drive after the temporary halt) or driving with an overhang would be exacerbated by this factor.

If the down-line TBM were driven with an overhang at the face, the upper part of the rear of the shield would have been pressed up against the ground overlying it and this could account for the larger outward displacements observed for this drive. This is also corroborated by the pore-water pressures measured in the same vicinity. It is useful that the pore-water pressure measurements were taken automatically and so the almost continuous data allow a more detailed interpretation of what happened compared with results from the rod extensometers and associated precise levelling which were taken manually and so at a much lower frequency. The location along the shield where the excess pore-water pressures start developing rapidly, in conjunction with the significant outward displacements measured, strongly support the suggestion that the down-line tunnel was being driven at this location with an overhang.
It has not been possible for the authors to locate continuous records of the thrust measurements made during the two drives. As noted by the discusser, the various shoves as the TBM was moved forward should have then been clearly evident (as they are for the face and grouting pressure measurements given in Fig. 6) and would have aided the understanding of the causes behind the mechanism of ground displacements and pore pressure response for both drives.

As a final point, it is perhaps worth mentioning that recent monitoring by Imperial College of two EPBM drives at Hyde Park, forming part of the Crossrail construction, does not indicate any outward displacements. This is most probably because the tunnels are considerably deeper than those at Dagenham. The field data are currently being analysed; care will be taken to check the TBM information available and whether the tunnels were driven in a particular way, for example with an overhang. Once again the authors thank the discusser for his very useful and astute discussion.

\section{REFERENCES}

Bezuijen, A., Nagel, F. \& Meschke, G. (2012). Flow around a TBM: A comparison of analytical and numerical methods. In Proceedings of geotechnical aspects of underground construction in soft ground, Rome, Italy (ed. G. Viggiani), pp. 173-179. London, UK: Taylor \& Francis.

Hight, D. W., McMillan, F., Powell, J. J. M., Jardine, R. J. \& Allenou, C. P. (2003). Some characteristics of London Clay. In Proceedings of the conference on characterisation and engineering, National University Singapore (eds T. S. Tan, K. K. Phoon, D. W. Hight and S. Leroueil), vol. 2, pp. 851-907. Rotterdam, the Netherlands: Balkema.

Standing, J. R. \& Selemetas, D. (2013). Greenfield ground response to EPBM tunnelling in London Clay. Géotechnique 63, No. 12, 989-1007, http://dx.doi.org/10.1680/geot.12.P.154. 